\title{
О.Б. Наумова
}

\section{ЭКСТРАВАГАНТНАЯ ЛИЧНОСТЬ В ТРАДИЦИОННОЙ КАЗАХСКОЙ КУЛЬТУРЕ (К ВОПРОСУ О ВРЕМЕНИ ФОРМИРОВАНИЯ ГРУППЫ САЛ-СЕРІ)}

\author{
Статья публикуется в соответствии с планом научно-исследовательских работ \\ Института этнологии и антропологии РАН.
}

\begin{abstract}
Статья посвящена группе сал-сері - казахских поэтов, исполнявших собственные произведения и известных экстравагантным поведением. Вопрос о времени возникновения группы автор решает на основе анализа их творчества и характерных черт личности. Салов и сері отличали чувство независимости, ощущение своей уникальности, индивидуализм лирики - черты, присущие социально-историческому типу личности Нового времени. Это дает основание полагать, что группа сал-сері сформировалась не раньше XIX в., а временем ее полноценного существования можно считать его вторую половину - период начавшегося постепенного перехода традиционного казахского общества к современному типу социальной организации.
\end{abstract}

Ключевые слова: поэты-песенники; антиповедение; индивидуальность; казахи; вторая половина XIX - начало XX в.

Под экстравагантностью мы понимаем эксцентричные формы образа жизни и поведения человека, которые могут нарушать нормы социума вплоть до антиповедения, вызывают удивление, восхищение или возмущение его членов. Экстравагантное поведение встречалось и встречается в любом обществе, но природа экстравагантности может быть различной, в частности можно с определенной долей условности говорить о традиционной и современной экстравагантности. В традиционном обществе экстравагантная личность, нарушая традиции, находилась в рамках самой традиции. Так, провокационное антиповедение русских юродивых парадоксальным образом имело целью взорвать самоуспокоенный мир обывателя, утратившего пафос религиозности [1. С. 55], и это было понятно всем окружающим. Можно сказать, что через экстравагантное поведение юродивых проявлялась их социальная роль, их общественная миссия. В обществах современных, с оформлением и укреплением идеи самоценности личности, экстравагантность обретает индивидуальный, индивидуалистский характер. Оригинальность, чудачества современного человека не имеют «общественного значения», они - манифестация его сильного ощущения собственной неповторимости и потребности заявить о ней публично (см.: [Там же. С. $121 ; 2])$.

Выделение двух социально-исторических типов экстравагантности позволяет поставить вопрос о времени формирования сал-сері - интереснейшей группы поэтов и музыкантов среди многочисленных категорий казахских народных певцов и сказителей. Сал и $c e p i^{1}$ - поэты, которые исполняли свои произведения на музыку собственного сочинения, аккомпанируя себе на струнном инструменте, чаще всего домбре. В научной литературе их называют акынами-мелодистами [3. C. 56], странствующими певцами-музыкантами [4. С. 71], устно-профессиональными носителями лирического начала [5. С. 87], поэтами-песенниками [6], поэтамиимпровизаторами и эксцентриками [7. С. 181]. Они появлялись на торжествах и свадьбах, организовывали игры и танцы. Современные исследователи утверждают, что салы всегда разъезжали группами, их сопровождали другие салы, певцы, музыканты-домбристы, борцы, фокусники и затейники. В аулах они устраивали целые театральные представления [6. С. 8; 7. С. 184]. Однако, по описаниям начала XX в., салы, похоже, путешествовали в одиночку. Очевидно, существовал и тот и другой способ музыкального выступления как салов, так и сері. Вероятно, именно сал-сері имел в виду П.И. Пашино, когда писал: «Есть у киргиз особенный род певцов, которые разъезжают из аула в аул и всю жизнь занимаются только пением» [8. С. 57]. Если это так, то, возможно, это первое упоминание о них в литературе. Рассказы о салах записали в начале XX в. А.И. Добросмыслов [9] и А.А. Диваев [10]; с людьми, видевшими этих поэтов-песенников, беседовал в 1920-х гг. А.В. Затаевич, оставивший нотные записи мелодий некоторых произведений салов и сері [11]; свидетели их творчества еще были живы в середине XX в. [3. С. 56-58]. Таким образом, судя по этим источникам, основной этап творчества сал-сері относится ко второй половине XIX в. Именно на этот период выпадают годы жизни самых известных салов и сері - Биржан-сала (1834-1897) и Ахан-серэ (18431913).

Обычно этих поэтов-музыкантов объединяют в одну группу и описывают вместе, хотя их облик и поведение заметно различались. Салы - эксцентрики, всем своим обликом и поведением они выламывались из рамок обыденной жизни; именно о них можно без оговорок говорить как об экстравагантных личностях. Сері же в своих внешних проявлениях не нарушали традиций, хотя тоже отличались от «обычных», «нормальных» казахов. 
Прежде всего бросалась в глаза необычная одежда салов. Е. Исмаилов, беседовавший с очевидцами выступлений салов и сері, приводит рассказ одного из своих собеседников (1886 г. рожд.), который в детстве выдел сала и не мог удержаться от смеха: «На голове Жанка-сала была невероятная по вышине коническая восьмиклинная шапка. Каждый клин ее был разного цвета, и к тому же на них еще болтались всевозможные украшения. На самом острие конической шапки был прикреплен пучок перьев филина. Время от времени, когда сал чуть опускал вниз голову, этот пучок качался и как будто бы приветствовал кого-то. Жанкасал был одет в длинную, ниже колен, сорочку с откидным воротником. И на ее плечах также торчали пучки перьев. На ногах у него полосатые узбекские ичиги, а широкие длинные брюки были опущены поверх голенищ» [3. С. 58]. А.И. Добросмыслов со слов стариков так описывал одеяния салов: «Один сал шил из шкур овец такие широкие шаровары, что взрослый человек свободно мог помещаться в каждой штанине. У другого воротник рубашки был шириною в 1/4 аршина. Сал по большей части одевался в бархат, в шелк и редко в простой халат, на руки надевал кольца и браслеты из серебра и золота. В ушах салов часто виднелись серебряные серьги величиною с добрый кулак» [9]. Как рассказывал А.В. Затаевичу А.Н. Букейханов, один из салов перья филина, которыми обычно украшают девичью шапку, втыкал себе прямо под кожу головы, «дабы украшение никогда не покидало его чела» [11. С. 330]. Характеризуя костюм салов, наблюдатели и исследователи называют его «шутовским», «вычурным», «фантастическим». Главное для него - оригинальность, неповторимость. «Сал всегда старался оригинальничать в костюме, и Боже упаси, если кто-нибудь позаимствует от него покрой, материю и цвет его костюма. Тогда он немедля придумывал какой-либо из ряда вон выходящий костюм. Например, заводил себе плащ из закопченной старой кошмы, подбив его шелковой, высокого качества материей» [10]. Таким образом, своим костюмом сал демонстративно нарушал обычай. Действительно, выделиться среди других можно было, вывернув традицию наизнанку, иногда в буквальном смысле: один из салов носил шубу из шкур хорьков мехом наружу (казахи шили одежду из шкур животных только мехом внутрь); другой пример «выворачивания» традиции - ношение девичьей одежды, украшений [7. С. 182]. Радикально решил проблему отрицания нормы еще один из них: он прошелся по аулу голым, «потому что на это не решится никто другой» [11. С. 330].

Такой же экстравагантностью отличалось поведение салов. Они демонстративно нарушали некоторые этикетные нормы. Могли въехать в аул на всем скаку, что было грубым нарушением традиции - такое позволялось только «черному» гонцу, в случае объявления о чьей-либо смерти [6. С. 6; 10; 12. С. 436]. За дастарханом они могли сидеть, уперев руки в бока [7. С. $183]$ - в позе, которая была под запретом в обычной жизни, потому что ассоциировалась со смертью и похоронами; так делала плакальщица или вдова, оплакивающая мужа [13. С. 214; 14. С. 331] (то же у киргизов:
[15. С. 150]); по сведениям Ш.Ж. Тохтабаевой, эту же табуированную позу принимали, чтобы сократить время агонии умирающего родственника [12. С. 434].

Отношения салов с девушками и женщинами были весьма вольными, сильно отступавшими от принятых норм. Девушки и молодые женщины занимали значительное место в творчестве и жизни сала: «Вся жизнь его проходила в поисках девиц, все его мечты, думы были сосредоточены на девицах, он жил и бредил ими, они были его идеалом, его кумиром» [10]. По сведениям А.И. Добросмыслова, сал для своих представлений выбирал «аул, который славился красотой девиц» [9]. Необычное поведение сала по отношению к женщинам начиналось уже с прибытия его в аул. Подъехав к юрте, он «падал» с коня и лежал на земле, пока девушки не помогали ему встать или даже на руках не относили его в дом. Они же разували сала, забирая монеты и украшения, которые он специально для этого случая засовывал за голенища сапог. В юрте девушки кормили сала с рук, даже жидкую пищу вливая ему в рот, поддерживая его голову [3. С. 60,$62 ; 7$. С. 187; 10]. Сал мог заигрывать с молодыми женщинами и девушками, не обращая внимания на присутствие их родственников. По А.И. Добросмыслову, в ауле он «проводил ночь в обществе одной или нескольких девушек, пел песни собственного сочинения, играл на домбре, одаривал подарками девиц и т.д.». Старики-казахи рассказывали ученому, что девушка, которая «предоставляла свою любовь салу», оставляла у себя его одежду и украшения. Сал мог «заочно» влюбиться и мог «за очаровательную лукавую улыбку милой отдать все свое состояние» [9]. А.А. Диваев пишет о ласках, расточаемых избранной салом девушки, с которой он проводил ночь и которая утром вместе с подругами выпроваживала его из аула [10]. Е.Д. Турсунов рассказывает о сале, который устраивал увеселение для молодежи, в ходе которого связывал парня и девушку и оставлял их одних в отдаленно стоящей юрте [7. C. 183, 185].

Салы совершали и другие необычные поступки, в которых, возможно, и не было прямого нарушения традиции, но которые вызывали изумление окружающих. «Так, например, сал вдруг режет своего любимого коня, вдруг свои хорошие новые одежды меняет на гнилые тряпки, вдруг снимает с себя и отдает первому встречному все свои драгоценности, да еще и лошадь со сбруей» [3. С. 60]. Вообще щедрость салов, видимо, была непременной характеристикой их личности: одежду и украшения сал раздавал девушкам аула, лошадь с седлом и дорогой упряжью оставалась хозяину юрты, в которой его принимали, «и сал отправлялся из аула пешком в одной лишь рубашке» [9].

Сері не были столь экстравагантны - «эксцентризм их не принимал столь крайних форм» [11. С. 330]. Если о салах исследователи часто говорят как о шутах и юродивых, то о сері - как о денди и рыцарях. Коннотации слов «сал» и «сері» ${ }^{2}$ в современном казахском языке хорошо передают разницу в поведении этих двух групп артистов. Слово сал с середины XIX в. переводили как «франт» [17. С. 33], «щеголь» [11. С. 218]; сал жігіт современным словарем переводится как 
«щеголеватый парень» [18]. Хорошо согласуется с образом казахского сала киргизское выражение салманап - праздная молодежь, проводящая жизнь в увеселениях и проказах [15. С. 624]. Значение слова серi по современным словарям, помимо поэта-песенника, «рыцарь», «богема» [19. С. 303].

Сері так же, как и салы, выделялись костюмом, но не его шутовским покроем и броской расцветкой, а чистотой и тонким вкусом, с которым он был сшит. Они тщательно следили за одеждой, шили ее из лучших материалов, с изящной отделкой [7. С. 191; 12. С. 361]. Таким же изысканным было их поведение: «...в их походке, движении, манере наблюдалось особое изящество», в общении - подчеркнутая учтивость [3. С. 58]. Их отношение с противоположным полом так же, как у салов, отличалось некоторой вольностью, но не переходило рамок приличий: «...им дозволялось лишь в стихах и песнях обращаться к понравившимся им девушкам или молодым женщинам в присутствии посторонних с выражением восхищения их красотой и пожеланием встречи наедине» [7. С. 192]. Однако в песнях они описывали не только свои мечты о встрече, но и реальные ночи, проведенные с любимой девушкой (см., напр., знаменитое стихотворение Ахан-сері, переводенное на русский язык разными поэтами; в переводе А.А. Коренева см.: [20. С. 271-272]).

Как можно оценить такое поведение салов и сері, можно ли назвать их экстравагантность традиционной? Для этого рассмотрим, кому позволялось отступление от нормативного поведения в традиционном обществе. Это были отдельные индивиды - шаманы, лекари, кузнецы, прорицатели, сказители, певцы - люди, чьи «социальные позиции вычленялись из нормы» [21. С. 113]. На материале южносибирских тюрков, близких в языковом и хозяйственно-культурном отношении казахам, эта группа исследуется в книге А.М. Сагалаева и И.В. Октябрьской, в разделе с говорящим названием «Лидер и изгой» [Там же. С. 110-117]. С одной стороны, эти люди - «духовные лидеры», их экстраординарные способности, сверхзнания ценились обществом, с другой стороны, они находились на социальной периферии, их деятельность вызывала опасения, как нечто, «имеющее отношение к миру иного», часто им приходилось влачить жалкое существование [Там же. С. 111]. Эти люди обладали способностями, талантами, знаниями и умениями гораздо выше обычных обладали «даром», что и давало им право на экстравагантность. Часто общество ожидало от них именно такого поведения. Однако существенна разница между двумя типами экстравагантности - той, которая была присуща традиционной личности, с одной стороны, и той, которую демонстрировали сал-сері - с другой. Необычное поведение первых (например, шаманов) трактовалось как послание духов обществу, весть из иного мира, их экстравагантность - экстравагантность традиционного типа, она имела «общественное значение».

Экстраординарные способности у «одаренных» индивидов традиционного общества, особенно ярко у шаманов, появлялись в результате так называемой шаманской болезни - болезненной процедуры, связанной с избранием человека духами для обретения ша- манского дара. Она хорошо известна народам Сибири, у казахов неоднократно изложена по рассказам баксы (шаманов) (см. подробнее: [22. С. 106-142]; одно из детальных описаний см.: [23]), продолжает существовать и в наши дни [24]. Обретение дара сказителями и певцами было подобным таковому у шаманов и лекарей: наличие духа-покровителя, передача дара по наследству, переживание состояния, сопоставимого с шаманской болезнью, получение дара во сне. Как и у шаманов, молодой сказитель не просто наследует талант отца, а забирает его дар [21. С. 94]. Сами «одаренные» считали свой дар бременем и, как правило, не хотели его принимать от духов-покровителей - ведь обретение дара не только бывало болезненным для его носителя из-за физических мучений, причиняемых шаманской болезнью, оно меняло всю жизнь человека, исключало его из среды «нормальных» людей. «Дар» не только давал почет, но и исключал его обладателя из ряда «нормальных» людей; поэтому обычно «избранный» сопротивлялся - он знал, что не сможет дальше жить, как все, станет «изгоем», в терминологии А.М. Сагалаева и И.В. Октябрьской.

Не столько во внешнем поведении, сколько именно в отношении к своему дару и - шире - к собственному «Я» состоит отличие традиционного типа экстравагантной личности от сал-сері. Традиционный человек, наделенный сверхспособностями, образно говоря, раб своего дара, он не свободен в своем выборе принять дар или отказаться от него. (Точнее, если человек отказывался принять дар, его ждали серьезные неприятности, болезни, вплоть до смерти.) Он отделяет себя от своего дара, его действия и способности как будто не принадлежат ему - ведь через человека действуют духи-покровители, его избравшие. У салов же и сері отношение к своему дару существенно отличалось от традиционного. Не дар их порабощал, а они владели даром, гордились им, гордились своей избранностью. Поэтому достоинство, гордость и даже заносчивость их характерные черты. Именно эти черты составляли основу экстравагантности сал-сері, экстравагантности нового типа - современной, долженствующей сообщить миру об их исключительности и неповторимости.

Тут мы подходим к важнейшему качеству салов и сері, системообразующему для характеристики их индивидуальности, которое и обусловливало их поведение и поэзию. Это - развитое самосознание, осознание себя личностью, острое чувство независимости, ощущение своей уникальности.

Предельно откровенно такое самосознание выражено знаменитым Биржан-салом:

Я сын Кожагула Биржан-сал,

Нет от меня никому вреда, я сам по себе.

Не склоняю головы ни перед каким человеком,

Я - сал, я - красавец, от кого мне зависеть!

Мне двадцать лет, не скрываю,

Я не позволяю недругам повелевать мною.

Я сэри, баловень народа,

Ни перед тобою, ни перед падишахом не склонюсь!

(На каз. яз. см.: [25. С. 363]. Цит. по: [7. С. 183].)

Показательно в этой связи, что, несмотря на явные различия во внешних проявлениях, в народном созна- 
нии салы и сері всегда объединяются в одну группу. Е.Д. Турсунов приводит примеры того, что и сами салы и сері могли называть себя и так и эдак, употребляя эти слова как синонимы [7. С. 189-191]. В казахском языке даже существуют объединяющее их слово салcepi, которое современный словарь переводит как «разносторонне творческие личности», и обобщенное понятие сал-серілік - «то, что свойственно разносторонне творческим людям». Объясняется это, несомненно, тем, что общее для них качество - непохожесть на всех, неслиянность с массой - важнее внешних различий внутри их группы. Яркая индивидуальность была присуща не только поведению сал-сері, но и их творчеству, что было еще более весомой причиной объединения их в одну группу. Индивидуализмом своей лирики они отличались от других групп казахских музыкантов (акынов, жырау, жыршы). Специально исследовавший традиционное и индивидуальное в творчестве салов и сері Ш.Т. Керимов приходит к выводу, что «если в прежней устной литературе на первом плане были интересы всего общества, без выделения личного, то теперь в поэзии стали преобладать индивидуальное начало, судьба отдельной личности» [6. С. 5].

Яркий индивидуализм и сильное личностное начало салов и сері позволяют уточнить время появления этой категории казахских поэтов-музыкантов. Обычно исследователи или не затрагивают этот вопрос, или пишут довольно расплывчато о древности происхождения салсері. Только Е.Д. Турсунов в своей насыщенной интересными фактами работе посвятил специальную главу «возникновению типа сал и сэри» [7. С. 171-201]. Он относит их появление к глубокой архаике - эпохе классообразования, времени действия ритуальных тайных союзов. Сопоставляя казахских салов и сері с военным тайным союзом ареоев Полинезии, он приходит к выводу, что происхождение этой группы поэтовартистов «является следствием разложения ритуального тайного союза» [Там же. С. 181], и время «возникновения ранних салов» относит к началу нашей эры [Там же. С. 201]. Правомерность такого сопоставления разнокультурных и разновременных явлений вызывает большие сомнения, и аргументация Е.Д. Турсунова не очень убедительна, тем более что он сам признает, что «у нас нет сведений о военной деятельности салов, ибо тайные союзы у тюрко-монгольских народов исчезли еще в древности» [Там же. С. 184]. Кроме того, не ясно, почему же до середины XIX в. не было упоминаний об этой группе, если она существовала по крайней мере в течение нескольких столетий до этого?

Представляется, что чуть ближе к истине позиция Е. Исмаилова: «Вопрос о том, когда окончательно сформировались традиции салов и серэ, еще детально не изучен. Ни в сказках, ни в древнем эпосе о них не упоминается. Тем не менее, если считать, что знахари, шаманы и серэ сходны между собой, их появление следует отнести к незапамятным временам нашей истории, хотя поэтические функции этих веселых бродяг и скоморохов могли сформироваться никак не раньше XIX в.» [3. С. 64].

Согласно этому противоречивому размышлению Е. Исмаилова, существовало якобы две группы, не совпадающие хронологически. Одна - древняя (с «незапамятных времен»), не имевшая «поэтических функций»; и даже нет уверенности, что она носила имя салсері (гипотетически это могли быть группы артистов типа юродивых и скоморохов). И другая - появившаяся в XIX в., та, что известна как сал-сері, поэзия которых была квинтэссенцией их личности. Похоже, что предположения о древности именно сал-сері чисто умозрительны, источники, на которых основаны такие предположения неизвестны. Время же появления реальных сал-сері, т.е. описанных в литературе, - XIX в. Однако, пожалуй, только Ш.Т. Керимов стоит на этих позициях - он обоснованно полагает, что «к выходу на арену нового типа (курсив мой. - О.Н.) певцов, называемых сал и сері» привели социальные и историкокультурные процессы XIX в. [6. С. 5].

Именно личности салов и сері дают подтверждение этой точки зрения. Известно, что индивидуальность, личность - явление социально-историческое, эпоха накладывает отпечаток на ее форму, проявления, взаимоотношение с обществом. Л.М. Баткин, рассматривавший личность эпохи Возрождения, т.е. эпохи перехода от Средних веков к Новому времени, от традиционного к современному обществу, попытался сформулировать эту разницу: «Ярко своеобразные люди встречались, конечно, всегда и всюду... однако это не означает, что во всякую эпоху такие люди сами дорожили в себе - и общество в них - именно личной оригинальностью, или хотя бы признавали ее естественным человеческим свойством, или вообще замечали и знали, что это такое» [26. С. 3] $]^{3}$. Философы, изучающие проблему индивидуальности, считают, что в обществе доиндустриальном «человеческое «Я» оценивается не само по себе, но лишь в контексте его причастности целому (роду, полису, Богу, социальной системе), сохранение и стабильность которого составляет приоритетную ценность. Частным случаем подобного отношения является восприятие индивидуальности как прямой угрозы обществу» [29. С. 103].

Именно о таком восприятии сверходаренных людей говорят А.М. Сагалаев и И.В. Октябрьская, указывая на их «изгойничество» в традиционном обществе. Но были ли изгоями сал-сері? Источники не свидетельствуют об этом. Скорее, они были «баловнями народа», как называет себя Биржан-сал. Их с радостью встречали в аулах, слушали их пение и смотрели представления, одаривали подарками. В юрте салам «отводилось почетное место выше старейшин - аксакалов, султанов, биев. Все люди уступали дорогу салу» [7. С. 183]. А.В. Затаевич пишет, что салы в казахской среде «производили впечатление каких-то избранников судьбы, людей высшего ранга, которым все дозволено» [11. С. 330]. Почтение к салам и сері и «разрешение» общества на нарушение традиции отчасти было связано с традиционным взглядом на «избранников» духов. Само их антиповедение имело силу традиции, именно таких действий от них ожидали. (Так, муж женщины, которой посвящал песни сері, «считал делом чести встретить у себя дома сэри всякий раз, когда сэри приезжал в этот аул» [7. С. 192-193].) 
Очевидно, что архаический страх перед опасностью, которую несет «инаковость», «чуждость» сверходаренных индивидов, в отношении к салам и сері уже отошел в прошлое ${ }^{4}$, что также свидетельствует о новом качестве их личности. Таким же образом можно трактовать и попытки родных вернуть своих экстравагантных родственников к «нормальной» жизни. Салы и сері происходили из зажиточных семей, а их разъезды и многочисленные наряды наносили немалый материальный ущерб их семейно-родственному кругу. По сведениям А.И. Добросмыслова, из посещаемых аулов сал возвращался без лошади и одежды, он продолжал такой образ жизни, «пока не проматывал своего состояния или не приходил в себя под влиянием какого-нибудь благоразумного родственника. Радикальным средством для вразумления, как говорят, была женитьба» [9]. Похоже, что окружающие не воспринимали сал-сері как носителей определенной социальной роли, от которой нельзя отойти. Вряд ли можно представить, например, что родня баксы - представления о личности которого полностью определялись традиционным мировоззрением - могла бы уговаривать его перестать шаманить.

Понятие авторства тоже может служить хронологическим индикатором появления группы сал-сері. Литературоведы связывают современное понимание категории авторства с категорией личности и относят его возникновение в Европе к началу Нового времени [30. С. 20; 31. С. 232], т.е. к переходному периоду от домодерного общества к современному. Ш.Т. Керимов на основе анализа текстов многих салов и сері отмечает, что «в них присутствуют сила авторского сознания и чувство своего превосходства над другими... авторы особо подчеркивают свое "Я” и стараются познакомить со своим произведением как можно большее число людей; они сопоставляют свои песни с произведениями предшественников и современников и при этом обязательно указывают свое имя, а иногда и род, имя отца» [6. С. 18-19], в отличие от анонимной фольклорной традиции.

Показательно и описание салами и сері личного опыта в своих произведениях. При индивидуалистском характере поэзии салов и сері и их «вольном» поведении очень большое место в их песенном творчестве занимает любовная лирика, причем именно их собственные любовные переживания («Что ж может быть прекраснее на свете, / Чем ранние мои отъезды эти / От девушки, ласкающей меня?» Цит. по: [3. С. 67]). Е.Д. Турсунов подсчитал, что у Биржан-сала больше половины из всех его стихотворений «посвящены любовной тематике» или содержат «мотивы любви и земных радостей бытия» [7. С. 186]. В своих песнях салы и сері пели и о совершенно конкретных вещах и событиях своей жизни, не обязательно романтичных, но непременно личных, автобиографичных. Так, в песне «Жанбота» Биржан-сал обращается к волосному управителю с жалобой на другого волостного управителя, который хотел отнять его домбру [3. С. 67]. Автобиографичность песен салов и сері делает их чрезвычайно разнообразными, так как любой случай из собственной жизни, любое переживание могут стать предметом поэзии. «Неповторимость достигается прежде всего характерной для творчества поэтовпесенников конкретикой и отходом от наставлений и назиданий, что было присуще поэзии жырау и некоторых акынов. Надо сказать, что салы и сері в основном создавали свои песни по конкретному случаю, и это. безусловно, придавало им как реалистичность, так и оригинальность» [6. С. 20]. Эту черту - использование собственного опыта - литературоведы считают «одной из примет становления авторства нового, современного типа» [30. С. 353]. Таким образом, категория авторства также привязывает сал-сері ко второй половине XIX в. - времени нараставшей модернизации в хозяйственной, социальной и политической жизни казахов, связанной с включением Казахстана в состав Российской империи и постепенным вовлечением его в орбиту политического и экономического влияния индустриально развитых обществ.

Исходя из всего сказанного, салов и сері можно назвать провозвестниками модерности в историческом развитии казахского социума. Они представляют собой новый социально-исторический тип экстравагантной личности, личности, появившейся на переломе эпох, в период перехода от традиционного к современному обществу.

\section{ПРИМЕЧАНИЯ}

\footnotetext{
${ }^{1}$ Казахская буква $i$ обозначает призвук, т.е. очень краткий и неясный звук. Он может передаваться русскими буквами $e$, э, $u$, в связи с чем в русскоязычной литературе разного периода казахское слово сері писалось сэри, серэ, сере и т.п.

2 Этимология этих слов остается неясной, а приводимые объяснения их происхождения не очень убедительны [3. С. 61-63, 64; 7. С. 194-196; 16. C. 40-41].

3 Л.М. Баткин вообще считает, что «личность» появляется лишь в эпоху Возрождения. О людях Средневековья и более ранних эпох он предлагает говорить как об «индивидах», используя термин «традиционалистский индивид» [26. С. 4-8]. Его точка зрения оспаривается историками и этнографами [27. С. 379-383; 28. С. 39-40].

${ }^{4}$ Впрочем, есть сведения, что не всегда и не везде салы пользовались признанием. А.И. Добросмыслов со слов казахов пишет, что сал мог «капризничать», т.е. вести себя, не считаясь с обычаем, «только там, где он рассчитывал на верный успех, в аулах же влиятельных султанов и богатых киргиз сал вел себя вполне прилично, так как иначе ему могло бы не поздоровиться» [9]. Возможно, это связано с большей исламизированностью благородных сословий (белой кости) и богатых скотоводов. Шутовское же поведение салов не вписывалось рамки исламских приличий. По сведениям Е. Исмаилова, муллы и ишаны объявили Биржан-сала и Ахан-сері «нарушителями закона Ислама», последнего упрекали в незнании шариата и неуважении религии [3. С. 63]. В любом случае говорить на основе этих материалов о салах и сері как об изгоях можно лишь с большой натяжкой.
}

\section{ЛИТЕРАТУРА}

1. Юрков С.Е. Под знаком гротеска: антиповедение в русской культуре (XI - начало XX в.). СПб. : Летний сад, 2003.210 с.

2. Лотман Ю.М. Русский дендизм // Лотман Ю.М. Беседы о русской культуре. Быт и традиции русского дворянства (XVIII - начало XIX века). СПб. : Искусство, 1994. С. 123-135. 
3. Исмаилов Е. Акыны : монография о творчестве Джамбула и других народных акынов. Алма-Ата : Казгосиздат худож. лит., 1957.340 с.

4. Маргулан А.Х. О носителях древней поэтической культуры казахского народа // М.О. Ауэзову : сб. ст. к его шестидесятилетию. Алма-Ата : Изд-во АН КазССР, 1959. С. 70-89.

5. Курмангалиева М. О ритуально-магической стороне деятельности салов и серэ // Культура кочевников на рубеже веков (ХІХ-ХХ, ХХXXI вв.): проблемы генезиса и трансформации : тез. докл. Междунар. конф., Алматы, 5-7 июня 1995 г. Алматы., 1995. С. $87-88$.

6. Керимов Ш.Т. Проблемы традиционного и индивидуального в творчестве казахских поэтов-песенников (сал, сери) второй половины ХІХ и начала XX веков : автореф. дис. ... канд. филол. наук. Алма-Ата, 1991. 24 с.

7. Турсунов Е.Д. Возникновение баксы, акынов, сэри и жырау. Астана : Фолиант, 1999. 265 с.

8. Пашино П.И. Туркестанский край в 1866 году. Путевые заметки. СПб. : тип. Тиблена и К을. 1868.179 с.

9. Добросмыслов А. Салы у киргиз // Туркестанские ведомости. 1909. № 230.

10. Диваев А.А. Киргизский сал // Туркестанские ведомости. 1916. № 222.

11. Затаевич A.В. 1000 песен казахского народа (напевы и мелодии). Оренбург : Киргиз. гос. изд-во, 1925. LVIII, 403 с.

12. Тохтабаева Ш.Ж. Этикет казахов. Алматы : Дайк-Пресс, 2013. 500 с.

13. Гродеков Н.И. Киргизы и каракиргизы Сыр-Дарьинской области: юридический быт. М. : Вост. лит, 2011.566 с.

14. Диваев А.А. Казакские пословицы // В.В. Бартольду : туркестанские друзья, ученики и почитатели. Ташкент, 1927. С. $328-333$.

15. Киргизско-русский словарь / сост. К.К. Юдахин. М. : Сов. энцикл., 1965. 973 с.

16. Керимов Ш.Т. Проблемы традиционного и индивидуального в творчестве казахских поэтов-песенников (сал, сері) второй половины ХІХ и начала ХX веков : дис. ... канд. филол. наук. Алма-Ата, 1991. 155 с.

17. Валиханов Ч. Избранные произведения. М. : Вост. лит., 1986. 414 с.

18. Русско-казахский словарь. URL: https://sozdik.kz/ru (дата обращения: 15.02.2018).

19. Махмудов Х., Мусабаев Г. Казахско-русский словарь. 2-е изд. Алма-Ата : Каз. сов. энцикл., 1987.512 с.

20. Ахан-серэ. Как здорово! (пер. А. Коренева) // Поэты Казахстана. Л. : Сов. писатель, Ленинград. отд-ние, 1978. С. $271-272$.

21. Сагалаев А.М., Октябрьская И.В. Традиционное мировоззрение тюрков Южной Сибири. Знак и ритуал. Новосибирск : Наука, Сиб. отд-ние, 1990. $209 \mathrm{c}$.

22. Басилов В.Н. Шаманство у народов Средней Азии и Казахстана. М. : Наука, 1992. 324 с.

23. Наумова О.Б. Казахский баксы: история одной фотографии (публикация материалов Ф.А. Фиельструпа по казахскому шаманству) // Этнографическое обозрение. 2006. № 6. С. 77-85.

24. Ларина Е.И. Наумова О.Б. Представление о даре и аруаке и современное народное целительство у российских казахов // Эпическое наследие и духовные практики в прошлом и настоящем // Этнологические исследования по шаманству и иным традиционным верованиям и практикам. М. : ИЭА РАН. 2013. Т. 15, Ч. 1. С. 110-122.

25. Бес ғасыр жырлайды (Поэты пяти веков) : 2 томдық. Алматы : Жазуши, 1989. Т. 1. 384 бет.

26. Баткин Л.М. Итальянское Возрождение в поисках индивидуальности. М. : Наука, 1989. 272 с.

27. Гуревич А.Я. Индивид и социум на средневековом Западе. М. ; СПб. : Центр гуманитарных инициатив, 2015.423 с.

28. Артемова О.Ю. Колено Исава: Охотники, собиратели, рыболовы (опыт изучения альтернативных социальных систем) М. : Смысл, 2009. $560 \mathrm{c}$.

29. Чеснокова М.Г. Социально-философские основания психологического исследования индивидуальности // Социально-гуманитарные знания. 2013. № 1. С. 97-109.

30. Пешков И.В. F1, или Книга доказательств: теорема Шекспира как лемма авторства. М. : PИПОЛ классик ; T8RUGRAM, 2017. 576 с.

31. Пешков И.В. Р. Барт и М. Фуко о генезисе категории авторства // Liberal Arts in Russia. 2017. Vol. 6, № 3. P. 230-241. DOI: 10.15643/libartrus-2017.3.3

Olga B. Naumova, Institute of Ethnology and Anthropology, Russian Academy of Sciences (Moscow, Russian Federation). E-mail: olganaumova@mail.ru

AN EXTRAVAGANT PERSON IN TRADITIONAL KAZAKH CULTURE (ON THE PROBLEM OF THE FORMATION OF THE SAL-SERI GROUP)

Keywords: singing poets, violation of traditional behavioral norms, individuality, the Kazakh, the second half of the 19th - the beginning of the 20th century.

The article discusses the time of the formation of a group of Kazakh singing poets - the sal-seri. This problem has to be solved by studying the behavioral features and basic personal traits of the poets who composed melodies to their own verses and performed their own songs themselves.

The information concerning the group refers to the second half of the $19^{\text {th }}$ century. The primary sources the research is based on consist in the products of the sal-seri while the secondary ones are presented by the information concerning their appearance, behavior and lifestyle, as well as their relationship with the surrounding community. The last data were collected in the beginning of the $20^{\text {th }}$ century by the Russian scientists who fixed the stories of those who had seen the Kazakh sal-seri while the Kazakh scientists who worked in the middle of the $20^{\text {th }}$ century based their work on the memories of eyewitnesses, who had watched the sal and seri performances.

The sal-seri were extremely extravagant in their manner of dressing and the way of behavior. The clothes of the sals were clownish, their behavior was eccentric while the costume and the manners of the seri were distinguished by deliberate refinement and grace. Both of them violated the traditional norms of behavior. In particular, their relations with the female sex were very liberated. The traditional society allowed some of its own members to violate the custom. These were individuals with extraordinary abilities, exceptional knowledge and skills like shamans, healers, visionaries, storytellers, singers etc. They were allowed to behave eccentrically, moreover from some of them such kind of behavior was expected. However, there is a significant difference between two following types of extravagance. The first one was inherent to the traditional personality, while the second one was shown by the sal-seri. The unusual behavior of a traditional person (for example, a shaman) was interpreted as a message given by spirits to the society, a message from another world. The extravagance of a shaman had a "social significance" while he himself considered his own gift as a burden. On the contrary, the sal-seri were proud of their gift; on the basis of analysis of their behavior and sings, one can assert that their extravagance to be individualistic, as it represented the manifestation of their own uniqueness, the desire to declare themselves in the public way. The sal-seri's extravagance and the type of their personality can be called modern in contrast to the traditional type of personality and extravagance.

There is an opinion in the works on history and folklore that the sal-seri group has its roots in the ancient times. Its appearance is considered to be a result of the disintegration of the military secret societies of the Turkic-Mongolian tribes in the time of class formation. However, the peculiarities of the sal-seri that characterize them as bright personalities and the individualism reflected in their songs emphasizing their own authorship in contrast to the traditional anonymity has made it possible to affirm that the essential condition for 
this group to be formed was the junction of tradition and modernity that appeared during the gradual transformation of the economic and social foundations in the traditional Kazakh society in the second half of the $19^{\text {th }}$ century.

\section{REFERENCES}

1. Yurkov, S.E. (2003) Pod znakom groteska: antipovedenie v russkoy kul'ture (XI - nachalo XX v.) [Under the sign of the grotesque: anti-behavior in Russian culture (the 11th - early 20th century)]. St. Petersburg: Letniy sad.

2. Lotman, Yu.M. (1994) Besedy o russkoy kul'ture. Byt i traditsii russkogo dvoryanstva (XVIII - nachalo XIX veka) [Conversations about Russian culture. Life and traditions of the Russian nobility (the 18th - early 19th century)]. St. Petersburg: Iskusstvo. pp. $123-135$.

3. Ismailov, E. (1957) Akyny. Monografiya o tvorchestve Dzhambula i drugikh narodnykh akynov [Akyny. Monograph on the works of Dzhambul and other folk akyns]. Alma-Ata: Kazgosizdat khudozh. lit.

4. Margulan, A.Kh. (1959) O nositelyakh drevney poeticheskoy kul'tury kazakhskogo naroda [About the bearers of the Kazakh ancient poetic culture]. In: M.O. Auezov. Sb. statey k ego shestidesyatiletiyu [M.O. Auezov. A collection of articles to his sixtieth birthday]. Alma-Ata: AS KazSSR. pp. 7089.

5. Kurmangalieva, M. (1995) O ritual'no-magicheskoy storone deyatel'nosti salov i sere [On the ritual and magical side of the activity of salas and seres]. Kul'tura kochevnikov na rubezhe vekov (XIX-XX, XX-XXI vv.): Problemy genezisa i transformatsii [Nomad culture at the turn of the century (19th 20th, 20th - 21st centuries): Problems of genesis and transformation]. Proc. of the International Conference. Almaty, June 5-7, 1995. Almaty: [s.n.]. pp. 87-88.

6. Kerimov, Sh.T. (1991) Problemy traditsionnogo i individual'nogo v tvorchestve kazakhskikh poetov-pesennikov (sal, seri) vtoroy poloviny XIX $i$ nachala XX vekov [The problems of the traditional and individual in the work of Kazakh poets-songwriters (sal, series) of the second half of the 19 th and early 20th centuries]. Abstract of Philology Cand. Diss. Alma-Ata.

7. Tursunov, E.D. (1999) Vozniknovenie baksy, akynov, seri i zhyrau [The emergence of buksy, akyns, seri and zhirau]. Astana: Foliant.

8. Pashino, P.I. (1868) Turkestanskiy kray v 1866 godu. Putevye zametki [Turkestan in 1866. Travel notes]. St. Petersburg: Tiblen i Ko.

9. Dobrosmyslov, A. (1909) Saly u kirgiz [Sals at the Kyrgyz]. Turkestanskie vedomosti. 230

10. Divaev, A.A. (1916) Kirgizskiy sal [Kyrgyz Sal]. Turkestanskie vedomosti. 222.

11. Zataevich, A.V. (1925) 1000 pesen kazakhskogo naroda (napevy i melodii) [1000 songs of the Kazakh people (tunes and melodies)]. Orenburg: Kirgizskoe gos. izd-vo.

12. Tokhtabaeva, Sh.Zh. (2013) Etiket kazakhov [Etiquette of the Kazakhs]. Almaty: Dayk-Press.

13. Grodekov, N.I. (2011) Kirgizy i karakirgizy Syr-Dar'inskoy oblasti: yuridicheskiy byt [Kirghiz and Karakirgiz of the Syr-Darya region: legal life]. Moscow: Vostochnya literatura.

14. Divaev, A.A. (1927) Kazakskie poslovitsy [The Kazakh proverbs]. In: Shmidt, A.E. \& Betger, E.K. (eds) Bartol'du V.V. Turkestanskie druz'ya, ucheniki i pochitateli [To V.V. Barthold from Turkestan friends, students and admirers]. Tashkent: [s.n.]. pp. 328-333.

15. Yudakhin, K.K. (1965) Kirgizsko-russkiy slovar' [Kyrgyz-Russian Dictionary]. Moscow: Sovetskaya entsiklopediya.

16. Kerimov, Sh.T. (1991) Problemy traditsionnogo $i$ individual'nogo v tvorchestve kazakhskikh poetov-pesennikov (sal, seri) vtoroy poloviny XIX $i$ nachala XX vekov [The problems of the traditional and individual in the work of Kazakh poets-songwriters (sal, series) of the second half of the 19 th and early 20th centuries]. Philology Cand. Diss. Alma-Ata.

17. Valikhanov, Ch. (1986) Izbrannye proizvedeniya [Selected Works]. Moscow: Vostochnya literatura.

18. Sozdic.kz. (n.d.) Russko-kazakhskiy slovar' [Russian-Kazakh Dictionary]. [Online] Available from: https://sozdik.kz/ru (Accessed: 15th February 2018)

19. Makhmudov, Kh. \& Musabaev, G. (1987) Kazakhsko-russkiy slovar' [Kazakh-Russian Dictionary]. 2nd ed. Alma-Ata: Kaz. sov. entsikl.

20. Akhan-sere. (1978) Kak zdorovo! [That's lovely!]. In: Vinokurov, E.M. (ed.) Poety Kazakhstana [Poets of Kazakhstan]. Leningrad: Sovetskiy pisatel'. pp. 271-272.

21. Sagalaev, A.M. \& Oktyabrskaya, I.V. (1990) Traditsionnoe mirovozzrenie tyurkov Yuzhnoy Sibiri. Znak $i$ ritual [The traditional worldview of the Turks of southern Siberia. Sign and ritual]. Novosibirsk: Nauka.

22. Basilov, V.N. (1992) Shamanstvo u narodov Sredney Azii i Kazakhstana [Shamanism among the peoples of Central Asia and Kazakhstan]. Moscow: Nauka.

23. Naumova, O.B. (2006) Kazakhskiy baksy: istoriya odnoy fotografii (publikatsiya materialov F.A. Fiel'strupa po kazakhskomu shamanstvu) [The Kazakh buksy: the history of a photograph (F.A. Fielstrup's materials on Kazakh shamanism)]. Etnograficheskoe obozrenie - Ethnographic Review. 6. pp. 77-85.

24. Larina, E.I. (2013) Naumova O.B. Predstavlenie o dare i aruake i sovremennoe narodnoe tselitel'stvo u rossiyskikh kazakhov [The idea of gift and Aruac and modern folk healing among Russian Kazakhs]. In: Kharitonova, V.I. (ed.) Epicheskoe nasledie i dukhovnye praktiki v proshlom i nastoyashchem [Epic heritage and spiritual practices in the past and present]. Moscow: IEA RAS. pp. 110-122.

25. Anon. (1989) Bes zasyr zhyrlaydy [Poets of Five Centuries]. Vol. 1. Almaty: Zhazushi.

26. Batkin, L.M. (1989) Ital'yanskoe Vozrozhdenie v poiskakh individual'nosti [Italian Renaissance in search of personality]. Moscow: Nauka.

27. Gurevich, A.Ya. (2015) Individ i sotsium na srednevekovom Zapade [The individual and society in the medieval West]. Moscow; St. Petersburg: Tsentr gumanitarnykh initsiativ.

28. Artemova, O.Yu. (2009) Koleno Isava: Okhotniki, sobirateli, rybolovy (opyt izucheniya al'ternativnykh sotsial'nykh sistem) [Esau's tribe: Hunters, gatherers, fishers (studying alternative social systems)]. Moscow: Smysl.

29. Chesnokova, M.G. (2013) Social and Philosophical Foundations of Psychological Study of Individuality. Sotsial'no-gumanitarnye znaniya. 1. pp. 97109. (In Russian).

30. Peshkov, I.V. (2017) F1, ili kniga dokazatel'stv: teorema Shekspira kak lemma avtorstva [F1, or the book of evidence: Shakespeare's theorem as a lemma of authorship]. Moscow: RIPOL klassik; T8RUGRAM

31. Peshkov, I.V. (2017) R. Barthes and M. Foucault on genesis of a category of authorship. Liberal Arts in Russia. 6(3). pp. 230-241. (In Russian). DOI: 10.15643/libartrus-2017.3.3 